\title{
The Impact of Inclusive Human Resource Practices on Individual Creativity: The Role of Job Crafting and Transformational Leadership
}

\author{
Qian Lu \\ School of Management, Wuhan University of Technology, Wuhan, P.R.China, 430070 \\ 1198246741@qq.com
} Keywords: Inclusive human resource practices(IHRP); Job crafting; Transformational leadership;
Individual creativity

\begin{abstract}
In the context of globalization, the change in the demographic structure and the flow of people around the world have resulted in more and more employees of different nationalities, regions, values, races and skins coexisting in enterprises. China is now in a transitional period, shifting from an investment type to an innovative one. This puts forward new requirements for individual creativity. Therefore, how to stimulate individual creativity has become a concern of management practitioners and researchers. Based on the theory of resource conservation, this study explores the positive impact of inclusive human resource practices on individual creativity. Job crafting plays a mediating role. Transformational leadership serves as a boundary condition and plays a moderating role.
\end{abstract}

\section{Introduction}

Under the background of a globalized economy, the rapid development of economic science and technology has transformed China's development strategy from an investment-oriented development to an innovative one. The country's innovation is affected by corporate innovation, and therefore this transformation requires a great deal of creativity for the company, and the creativity of the organization is determined by the level of individual creativity(Gong et al., 2013)[1]. These social backgrounds have caused practitioners and managers to pay attention to individual creativity.

The individual's creativity is inspired by the organizational practice. In the past, diversification management focused on and emphasized how diversification of employees can be converged, but the conflicts and conflicts between employees still exist(Roberson et al., 2017)[2]. Based on this, scholars have proposed inclusive management. Previous studies have only explored the impact of inclusive leadership and inclusive atmosphere on individual creativity(Pelled et al., 2010)[3]. The study of the impact of IHRP on individual creativity has not yet been discovered. Based on this, this study is devoted to exploring the potential mechanisms and boundary conditions for the impact of IHRP on individual creativity.

Based on the conservation theory of resources, individuals will actively obtain resources from the outside world to increase their own resources. Due to the diversification of employees, the external information obtained by individuals is not the same. Differences in background, culture, values, etc. between individuals make the understanding of roles among individuals different, and thus their roles will be different which may promote positive actions such as job crafting(Tims, Bakker , 2010)[4]. With the support of the organization of IHRP, individuals have greater autonomy and discretion, providing opportunities for individuals to job crafting. Previous studies have shown that job crafting has a positive effect on individual creativity. Therefore, it may believe that job crafting may have a mediating role in the impact of IHRP on individual creativity.

Research shows that the matching of leadership styles and management practices can further promote corporate performance(Yin, 2015)[5]. Transformational leadership may motivate subordinates to generate new ideas and put them into practice which is similar to IHRP. And transformational leaders tend to change the current state in order to achieve better results which is related to individual job crafting. So we believe that the matching of transformational leadership and IHRP can further promote individual job crafting(Wang, 2017)[6]. 
In summary, this study aims to explore the positive effects of IHRP on individual creativity through job crafting, and examines the moderating role of transformational leadership.

\section{Literature Review}

IHRP. The concept of inclusiveness first appeared in the research fields of social work and social psychology. With the continuous deepening of diversity research, inclusiveness has gradually entered the management field. From the point of view of the leadership member exchange relationship, inclusiveness advocates respecting employees, understanding employees, paying attention to employee feedback, and assuming employee responsibilities (Hantula D A, 2009)[7]. From a relational perspective, inclusiveness means being good at building good relationships with employees and encouraging employee participation (Carmeli, A., R. Reiter Palmon and E. Ziv, 2010)[8]. In general, inclusiveness refers to the adoption of a fair employment policy for diversified employees, integration of differences, and the use of individual advantages to allow employees to participate in decision-making (Nishii LH, 2013)[9]. In the context of China, it also has the unique meaning of error tolerance (Tang, 2015)[10].In summary, this study considers that inclusive human resources practice refers to a series of human resource management activities to respect employee differences, recognize employee value, tolerate employees' errors, give full play to their employees' differential potential, encourage employees to participate, which are adopted to achieve organizational goals and improve organizational performance.

Job Crafting. American scholars Wrzesniewski and Dutton (2001)[11] first put forward the concept of "job crafting" based on previous studies. They believe that job crafting is a series of changes that individuals make in their tasks, interpersonal relationships and self-cognition. They divided the job crafting into three dimensions, namely, the task crafting, the relational crafting and the cognitive craft. The task crafting refers to the changes in the number, scope and type of tasks; relationship crafting refers to the change in the quality and quantity of personal relationships; cognitive crafting refers to the change in the sense of the individual's sense of work.

Since then, Tims and B Akker (2010)[4] and other scholars have expanded the meaning of job crafting based on the work requirement-resource theory (JD-R) model, that is, job crafting is the product of the individual after the trade-off between the work needs and the individual abilities, and makes the behavior changes based on the tradeoffs. They divide job crafting into four dimensions of the increasing structural job resources, increasing social work resources, increasing challenging job demands, and decreasing hindering job demands. This study also uses this definition.

Transformational Leadership. Transformational leadership was first proposed by Downton, and its research can be regarded as the origin of transformational leadership. Later, Burns defined the transformational leadership through Maslow's hierarchy of needs theory in his book "leader theory". After that, scholars made different definitions of transformational leadership based on their research(Coad,2013)[12], as shown in Fig. 1.

Table 1 Transformational leadership definition

\begin{tabular}{ll}
\hline Scholars & \multicolumn{1}{c}{ Definition } \\
\hline Burns(1978) & $\begin{array}{l}\text { the motivation of the leaders to stimulate and encourage employees through higher ideas } \\
\text { and moral values, so that their subordinates can fully invest in their work. } \\
\text { by making employees aware of the importance of the tasks they undertake, stimulates the } \\
\text { high-level needs of their subordinates, and encourages the subordinates to sacrifice their } \\
\text { interests for the benefit of the organization and to achieve more than the desired results. } \\
\text { has special influence to the followers, stimulates the subordinates to sacrifice their own } \\
\text { interests to the organization, and inspires the subordinates' individualized care and } \\
\text { intelligence, so that the subordinates are willing to do their best and reach the group } \\
\text { goals. } \\
\text { can clarify or help clarify a vision that can be tried, even if this vision is difficult to } \\
\text { achieve, make people feel possible, by arousing the spirit of struggle, even temporarily } \\
\text { making sacrifices, or making satisfaction, fun and self-fulfillment. }\end{array}$ \\
Ackoff (2007)
\end{tabular}


Individual Creativity. In previous studies, the connotation of creativity is diversified because of the differences of research problems, research perspectives and research methods that scholars have paid attention to. By combing the literature, it is found that its definition can be broadly classified into three categories: First, the "view of the process" of creativity. Researchers who agree with this definition focus on the process of creative activities, and define creativity as "the process of analyzing and solving problems"(Perrysmith, 2006)[13].Secondly, the "trait view" of creativity. According to this view, creativity is a characteristic of an individual and can be distinguished from those of high creativity and low creativity according to certain characteristics(Oldham , 1996)[14].Third, the "result view" of creativity. In the field of creativity research, this view is the most influential and representative, and has been accepted by most scholars. It believes that creativity is a new, appropriate and useful idea of individuals or groups in an organization(Amabile, 1989)[15].

This study pays more attention to the result of the individual creativity. Therefore, this article adopts the connotation and definition of Amabile's result view, and thinks that individual creativity is a novel, suitable and useful idea for the individual or group in the organization.

\section{Hypotheses Development}

Inclusive Human Resource Practice and Individual Creativity. Based on the conservation theory of resources, with the support of the organization, individuals will not only try their best to maintain and protect their existing resources, but also try their best to acquire and develop new resources (Hobfoll, 1989)[16]. Inclusive human resource practice, as a resource for organizational input, can increase the staff's stock of resources, provide employees with diverse knowledge and skills, knowledge, skills, modes of thinking, opinions, and information. Diversity helps promote individual creativity (Shin et al., 2012)[17]. In addition, studies have shown that inclusiveness is a unique connotation of inclusive management in the context of China (Tang, 2015)[10]. The tolerance for individuals' different perspectives and failure can motivate individuals to be more willing to take risks in innovation and promote individual participation. Innovation motivation. Based on this, we assume that:

Hypothesis 1: IHRP have a positive impact on individual creativity.

Inclusive Human Resources Practice and Job Crafting. Based on the theory of conservation of resources, individuals will acquire role relevant information from management practices. Inclusive human resource practice focuses on employee participation and encourages employees to innovate which will enable individuals to perceive autonomy and discretion in shaping work roles and provide opportunities for remolding individual jobs. IHRP advocate the inclusion of individual errors. This means that the negative consequences of job crafting can be forgiven and understood by the organization(Nishii LH, 2013)[9]. Therefore, individuals are more motivated to job crafting.

Hypothesis 2: IHRP have a positive effect on job crafting.

Job Crafting and Individual Creativity. Job crafting refers to changes in work tasks, relationships, and self-perception. The greatest feature of job crafting is autonomy. Studies have shown that high levels of personal autonomy are associated with the generation of creative ideas (Gong et al., 2013)[1]. Based on the theory of conservation of resources, the interaction of various resources can promote the individual's creativity. During the process of job crafting, the individual will work autonomously and re-determine the work content according to the allocation of various resources. In this way, resources will collide with each other in the redistribution of resources, which will be conducive to the emergence of new ideas and thus generate greater creativity. Based on this, we assume that:

Hypothesis 3: Job crafting has a positive effect on individual creativity.

Based on the above assumptions, we assume that:

Hypothesis 4: Work reshapes the impact of IHRP on individual creativity.

Transformational Leadership as a Moderator. Based on the theory of conservation of resources, transformational leaders are good at using existing resources, encouraging individuals to 
actively innovate, change existing conditions, and strive to acquire new resources. Leadership is the spokesperson and interpreter of the organization's practice. Only if the leaders correctly communicate the organization's wishes to the employees, can organization and practice be successfully implemented. Transformational leaders advocate that individuals realize their own ideas and visions and give individuals greater autonomy(Coad,2013)[12]. This is consistent with the idea of inclusive human resources practice. Therefore, transformational leadership can well convey the organizational thinking of IHRP which make individuals more willing to acquire new resources, realize their own new ideas, and then generate greater creativity. Therefore, we assume that:

Hypothesis 5: Transformational leadership moderates the impact of IHRP on individual creativity.

Transformational leadership will encourage subordinates to do everything they can to achieve their vision and improve their own work. Therefore, individuals will be more willing to use the participation of employees involved in the implementation of inclusive human resources and participate in their own role-building which may promote their more job crafting behavior. Transformational leadership will also motivate individuals to plan their vision(Coad,2013)[12]. When individuals have a vision for the future, they will have the idea of changing their existing job roles. IHRP will embrace the mistakes of employees and give employees courage to reshape their roles. In turn, there will be greater job crafting motivations. In summary, we assume that:

Hypothesis 6: Transformational leadership moderates the impact of IHRP on job remodeling.

Assuming comprehensive hypotheses 4 and 6, we propose:

Hypothesis 7: Transformational leadership moderates the impact of IHRP to individual creativity through job crafting.

\section{The Construction of a Research Model}

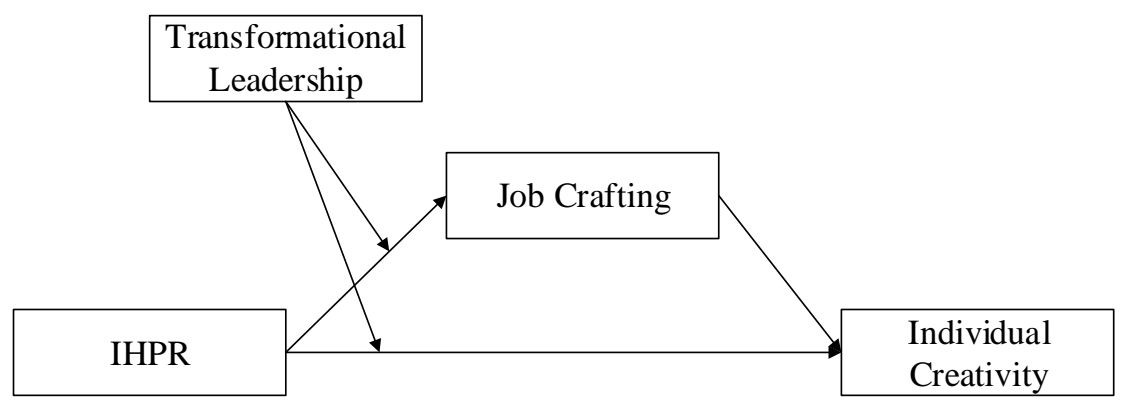

Figure 1. Finite Theoretical hypothesis model

This study mainly discusses the relationship between IHRP, job crafting, and individual creativity, as shown in the conceptual model above. Transformational leadership moderates the impact of IHRP on individual creativity. Based on the theory of conservation of resources, inclusive human resource practice emphasizes individual participation, giving individuals greater autonomy and discretion, so that individuals will be more motivated and have the opportunity to implement job crafting behavior. Job crafting involves the creation and implementation of new ideas, which in turn will promote individual creativity. Transformational leaders are good at using existing resources, encouraging individuals to actively innovate, change existing status, and strive to acquire new resources. When the individual's leadership is a transformational leader, the individual will be more willing to participate in job crafting because he or she has the dual support of leadership and organization. Therefore, we believe that transformational leadership moderates the impact of IHRP to individual creativity through job crafting. 


\section{Conclusion}

This study proposes the positive impact of IHRP on individual creativity, discusses the mediating role of job crafting, and explores the moderating role of transformational leadership. The study has the following contributions. First, few studies have explored the impact of IHRP. This study contributes to inclusive research by proposing its impact on individual creativity. Second, although studies have examined the impact of job crafting on individual creativity, few studies have researched job crafting as a mediating variable. This paper contributes to job crafting research by discussing the mediating role of job crafting in the relationship between inclusive human resource practice and individual creativity. Third, the paper considers that the matching of IHRP and transformational leadership can further promote individual creativity, and shows that the matching of leadership styles and human resource practices has a positive effect, and contributes to the leadership and organization of the literature.

\section{Acknowledgements}

The authors acknowledge the Excellent Dissertation Cultivation Funds of Wuhan University of Technology (2017-YS-026).

\section{References}

[1] Y. Gong, T.Y. Kim, D.R. Lee, and J. Zhu, A multilevel model of team goal orientation, information exchange, and creativity. Academy of Management Journal, Vol. 56 (2013), p827-851.

[2] Q. Roberson, A.M. Ryan, and B.R. Ragins, The Evolution and Future of Diversity at Work. Journal of Applied Psychology, Vol. 102 (2017)No3, p483.

[3] L.H. Pelled, G.E. Ledford, Jr, and S.A. Mohrman, Demographic Dissimilarity and Workplace Inclusion. Journal of Management Studies, Vol. 36 (2010), p1013-1031.

[4] M. Tims, and A.B. Bakker, Job crafting: Towards a new model of individual job redesign. Sajip South African Journal of Industrial Psychology, Vol. 36 (2010), p1-9.

[5] X.F. Yin, Research on Mechanism of Leadership Style Affection on Effectiveness of Human Resource Management. Journal of Chongqing University of Technology (2015).

[6] H.J. Wang, E. Demerouti, and P.L. Blanc, Transformational leadership, adaptability, and job crafting: The moderating role of organizational identification. Journal of Vocational Behavior, Vol. 100 (2017), p185-195.

[7] D.A. Hantula, Inclusive Leadership: The Essential Leader-Follower Relationship. Psychological Record, Vol. 59 (2009), p701-704.

[8] A. Carmeli, R. ReiterPalmon, and E. Ziv, Inclusive Leadership and Employee Involvement in Creative Tasks in the Workplace: The Mediating Role of Psychological Safety. Creativity Research Journal, Vol. 22 (2010), p250-260.

[9] L.H. Nishii, The benefits of climate for inclusion for gender-diverse groups. Academy of Management Journal, Vol. 56 (2013), p1754-1774.

[10]N. Tang, Y. Jiang, C. Chen, Z. Zhou, C.C. Chen, and Z. Yu, Inclusion and inclusion management in the Chinese context: an exploratory study. International Journal of Human Resource Management, Vol. 26 (2015) , p856-874.

[11] A. Wrzesniewski, and J.E. Dutton, Crafting a Job: Revisioning Employees as Active Crafters of Their Work. Academy of Management Review, Vol. 26 (2001), p179-201.

[12] A.F. Coad, and A.J. Berry, Transformational leadership and learning orientation. Leadership \& Organization Development Journal, Vol. 19 (2013), p164-172.

[13] J.E. Perrysmith, Social Yet Creative: The role of social relationships in facilitating individual creativity. Academy of Management Journal, Vol. 49 (2006), p85-101.

[14] G.R. Oldham, and A. Cummings, Employee Creativity: Personal and Contextual Factors at Work. Academy of Management Journal, Vol. 39 (1996), p607-634. 
[15] T.M. Amabile, R. Conti, H. Coon, J. Lazenby, and M. Herron, Assessing the Work Environment for Creativity. Academy of Management Journal, Vol. 39 (1996) , p1154-1184.

[16] S.E. Hobfoll, Conservation of resources. A new attempt at conceptualizing stress. American Psychologist, Vol. 44 (1989), p513.

[17] S.J. Shin, T.Y. Kim, J.Y. Lee, and L. Bian, Cognitive team diversity and individual team member creativity: A cross-level interaction. Academy of Management Journal, Vol. 55 (2012), p197-212. 